\title{
EKSISTENSI MANTAN PETINJU NASIONAL SEBAGAI PETARUNG PENCAK DOR KEDIRI MELALUI FILM DOKUMENTER POTRET "MICHAEL SPEED"
}

\author{
Kulsa Angelo \\ Alexandri Luthfi R. \\ RR. Ari Prasetyowati \\ Jurusan Film \& Televisi, Fakultas Seni Media Rekam, Institut Seni Indonesia Yogyakarta \\ Jl. Parangtritis km. 6.5 Yogyakarta Telp. (0274) 381047
}

\begin{abstract}
ABSTRAK
Penyutradaraan karya film dokumenter potret ini ialah untuk memberikan gambaran kehidupan seorang mantan petinju nasional dan petarung Pencak Dor di Kediri bernama Michael 'Speed' Sigarlaki, memperkenalkan adanya tarung Pencak Dor kepada masyarakat sekaligus menberikan cerminan buruknya kualitas tinju di Indonesia.

Objek penciptaan karya film dokumenter ini ialah tarung Pencak Dor Kediri dan Michael 'Speed' Sigarlaki. Karya ini dikemas menggunakan struktur bertutur tematis serta menerapkan gaya penceritaan cinema verite dan expository. Film Michael Speed banyak menggunakan handheld camera dan diegetic sound untuk merekam aktifitas subjeknya, subjek terkadang berbicara langsung ke arah kamera, dan di beberapa bagian digunakan juga metode wawancara untuk memperkuat informasi kepada penonton.

Pembahasan mengenai kisah hidup Michael Speed dalam memperjuangkan eksistensinya di dunia tarung dikemas ke dalam karya tugas akhir berbentuk film dokumenter potret dengan judul karya ilmiah Eksistensi Mantan Petinju Nasional Sebagai Petarung Pencak Dor Kediri Melalui Film Dokumenter Potret "Michael Speed". Perwujudan karya film dokumenter potret Michael Speed dikemas ke dalam 3 segmen pembahasan diantaranya, segmen 1 berisi pengenalan tarung Pencak Dor dan tokoh petarung bernama Michael Sigarlaki, segmen 2 membahas eksistensi serta konflik batin Michael Sigarlaki sebagai petarung Pencak Dor profesional, dan segmen 3 menjadi penutup yang menampilkan nilai-nilai humanisme dalam diri Michael Sigarlaki sebagai kepala keluarga.
\end{abstract}

Kata kunci: Penyutradaraan; Dokumenter Potret; Eksistensi Petarung Pencak Dor Kediri Michael Speed

\begin{abstract}
The directing of this portrait documentary is to provide an overview of the life of a former national boxer and the Pencak Dor fighter in Kediri named Michael 'Speed 'Sigarlaki, introducing the existence of Pencak Dor to the community while giving the poor reflection of the quality of boxing in Indonesia.

The object of the creation of this documentary film is fighting Pencak Dor Kediri and Michael ' Speed 'Sigarlaki. The work is packed using a thematic structure and applies storytelling-style cinema verite and expository. The Film Michael Speed used a lot of handheld cameras and diegetic sound to record the activities of his subjects, the subjects sometimes spoke directly towards the camera, and in some parts used also the interview method to reinforce the information to the audience.

The discussion on the life story of Michael Speed in the fight for his existence in the world of fighting is packed into the work of the end-task in the form of portrait documentary with the title of former national boxer existence as a combatant Pencak Dor Kediri through the portrait documentary "Michael Speed". The embodiment of the portrait documentary film Michael Speed is packed into three discussion segments, segment 1 contains the introduction of Pencak Dor's fighting and the warrior figure Michael Sigarlaki, Segment 2 discusses the existence and inner conflict of Michael Sigarlaki as a professional Pencak Dor fighter, and Segment 3 is the cover showing the values of humanism in Michael Sigarlaki as the head of
\end{abstract}

Key words: Direction; Documentary Portraits; "The existence of Pencak Dor Kediri Fighter Michael Speed" 


\section{Kulsa Angelo, Alexandri Luthfi R., RR. Ari Prasetyowati}

Eksistensi Mantan Petinju sebagai Petarung Pencak Dor Kediri melalui Film Dokumenter Potret "Michael Speed".

\section{PENDAHULUAN}

Dokumenter potret atau biasa disebut biografi adalah jenis film dokumenter yang isinya berkaitan dengan satu tokoh masyarakat atau lebih. Mereka yang dijadikan tema utama umumnya merupakan seseorang yang terkenal atau juga seseorang yang memiliki kehebatan, keunikan ataupun aspek menarik lainnya. Alasan memilih dokumenter potret dikarenakan dokumenter potret memiliki daya tarik untuk membuat penonton turut bersimpati terhadap si tokoh utama serta topik permasalahan ataupun fenomena yang sedang dialami, ditambah adanya dorongan untuk membuat karya film dokumenter potret yang lebih baik dari karya sebelumnya.

Objek dari film dokumenter tugas akhir ini adalah tarung bebas Pencak Dor, merupakan budaya kesenian asal kota Kediri yang sedang menjadi sorotan berbagai media online saat ini. Banyak dari kalangan masyarakat gemar menonton video pertarungan ekstrim ini di YouTube karena menampilkan kebrutalan penuh adrenalin dari setiap pertarungannya, atmosfer khas Islam seperti halnya shalawatan yang berpadu dengan iringan musik gamelan menyelimuti jalannya pertarungan juga turut menambah nilai keunikan Pencak Dor.

Alasan memilih Pencak Dor sebagai obyek film dokumenter tugas akhir ini adalah untuk menjawab rasa penasaran akan keseruan pada saat menyaksikan kesenian tarung Pencak Dor secara langsung serta adanya keinginan untuk berbagi informasi mengenai adanya tarung Pencak Dor yang banyak belum diketahui oleh masyarakat di Indonesia.

Michael Sigarlaki, atau yang biasa dipanggil Michael Speed merupakan salah satu petarung Pencak Dor yang hampir selalu memenangkan pertarungan. Pria kelahiran Manado 31 tahun silam ini memiliki profesi sebagai petarung Pencak Dor sekaligus pelatih Muay Thai di Tulungagung, Jawa Timur. Berlatar belakangkan sebagai mantan petinju nasional yang terbilang berprestasi mendorong rasa ingin untuk mengupas sepenggal kisah hidupnya serta menceritakan kembali kepada masyarakat melalui media film dokumenter potret yang mengisahkan perjalanan karier bertarung, prestasi dan eksistensi seorang petarung Pencak Dor bernama Michael Speed ini.

Alasan memilih Michael Sigarlaki sebagai tema utama di dalam film ini bermula saat melihat aksi pertarungannya di YouTube yang hampir selalu menang, ditambah munculnya rasa perihatin bercampur salut pada saat ia menceritakan kisah hidupnya yang penuh lika-liku untuk meraih gelar kejuaraan tinju di Indonesia serta keseriusannya dalam mempertahankan karier sebagai petarung Pencak Dor. Melihat besar kecintaannya akan dunia tarung membuat eksistensinya sebagai petarung tetap terjaga 
hingga detik ini meskipun bukan di ranah tinju tanah air lagi.

\section{IDE PENCIPTAAN}

Pada segmen 1 akan diperkenalkan tarung Pencak Dor Kediri dan kemudian mengerucut pada salah satu petarung bernama Michael Speed, saat memasuki segmen 2 Michael Sigarlaki akan memberikan pernyataan bahwa ia sangat menyukai dunia tarung, dan bertarung adalah cara terbaik baginya untuk menghidupi keluarga apapun itu risikonya, dan di segmen 3 akan diperlihatkan sisi humanism sosok Michael Sigarlaki yang sangat menyayangi keluarganya, sehingga pernyataan untuk berhenti bertarung pun pada akhirnya muncul diakhir film, ia tidak ingin terus menerus bertarung seperti saat ini, karena ia mengkhawatirkan kelangsungan hidup keluarganya jika nanti terjadi hal yang buruk padanya, serta hobinya menulis lagu cinta juga akan dimunculkan untuk menambah nilai-nilai humanism seorang Michael Sigarlaki yang akan menyanyikan lagu ciptaannya sendiri.

Film dokumenter potret “Michael Speed" akan dikemas menggunakan tipe pendekatan dokumenter cinema verite yang dipadukan dengan gaya ekspositori. Penggunaan pendekatan cinema verite bermaksud untuk mendapatkan informasi secara spontan bersamaan dengan suatu kejadian yang terekam kamera, sehingga realita dari kejadian yang terekam akan terasa sangat natural, dan untuk mempertegas informasi yang ingin disampaikan akan digunakan juga tipe ekspositori yang biasa menggunakan audio wawancara ataupun menambahkan teks agar dapat memudahkan penonton dalam memahami informasi dari film yang dibuat.

Secara garis besar teknis yang digunakan adalah teknik pengambilan gambar secara long take dan handheld camera yang bertujuan untuk mendapatkan momen-momen penting secara keseluruhan, sekaligus untuk mendapatkan ekspresi Michael yang bisa saja akan muncul secara tiba-tiba, baik itu ekespresi senang maupun sedih. Selain teknik long take akan digunakan juga teknik slow motion editing pada saat Michael Speed melancangkan pukulannya ke lawan.

Membangun kedekatan antara subjek dengan penonton sangatlah penting dalam proses pengkaryaan film dokumenter, tujuannya adalah untuk menahan perhatian penonton, memudahkan penonton dalam memahami baik alur cerita maupun informasi yang ingin disampaikan oleh pembuat film dokumenter melalui sudut pandang subjek, oleh itu perlu dilakukan pendekatan secara naratif dengan membangun konstruksi penuturan tiga babak yakni pengenalan, konflik, dan penyelesaian. Hal tersebut dapat dicapai dengan cara memperkenalkan sosok Michael Sigarlaki melalui prestasinya di dunia tinju, kemudian memunculkan aspek- 


\section{Kulsa Angelo, Alexandri Luthfi R., RR. Ari Prasetyowati}

Eksistensi Mantan Petinju sebagai Petarung Pencak Dor Kediri melalui Film Dokumenter Potret "Michael Speed".

aspek human interest dalam diri Michael Sigarlaki yang akan mencerminkan eksistensi dan konsistensinya untuk mencari nafkah di dunia tarung hingga saat ini, serta adanya konflik batin yang bergejolak seperti halnya rasa takut dan keterpaksaan untuk bertarung di Pencak Dor yang pada akhirnya ia leburkan dengan passion bertarung yang ia miliki sehingga ia berhasil membuktikan profesionalitasnya sebagai petarung Pencak Dor.

\section{KONSEP KARYA}

Konsep penyutradaraan dalam film dokumenter ini ialah memaparkan semangat bertarung Michael Speed melalui karya audio visual dengan menampilkan kejadiankejadian penting yang terekam oleh kamera, kejadian-kejadian tersebut akan disusun menjadi susunan gambar yang bercerita serta mampu memberikan informasi kepada penonton, baik informasi yang bersifat spontan maupun informasi yang akan disampaikan menggunakan metode wawancara, agar penonton mendapatkan informasi yang edukatif sekaligus menyaksikan kejadian-kejadian menarik yang akan menghidupkan suasana dari film ini.

Film dokumenter ini merupakan bentuk representasi potret seorang petarung Pencak Dor yang inspiratif, edukatif, dan menggugah rasa simpatik penonton terhadap subjek yang difilmkan, serta dapat memberikan sensasi adrenalin ketika penonton melihat dan mendengar suasana pertarungan Pencak Dor di Kediri. Durasi film dokumenter "Michael Speed" akan dibuat cukup singkat yakni kurang lebih 19 menit dan dibagi ke dalam 3 segmen. Pembagian durasi per segmennya berkisar 4-10 menit, dan setiap segmennya memiliki sub-sub tema pembahasan yang dirangkai secara tematis ke dalam tiap-tiap segmen, meskipun terdapat beberapa topik pembahasan dalam satu segmen secara keseluruhan masih dalam satu benang merah yakni semangat bertarung mantan petinju dalam pertarungan Pencak Dor Kediri untuk menunjukkan eksistensi sekaligus profesionalitas seorang petarung sejati.

Secara teknis subjektifitas dilakukan pada saat melakukan interview dan merekam kejadian-kejadian penting, dengan memberikan pertanyaan yang runtut serta mudah untuk dijawab oleh subjek, baik secara spontan maupun secara naratif, serta penerapan metode pengambilan gambar yang dibuat apa adanya tanpa skenario, namun tetap menjaga kualitas gambar dan kenyamanan mata penonton, serta saat proses penyusunan gambar di meja editing, agar film yang dibuat dapat bercerita sesuai dengan keinginan pembuat film.

Teknis penyutradaraan di dalam film dokumenter ini lebih mengacu pada hasil riset yang sudah diperoleh sebelumnya untuk dirancang menjadi alur cerita yang masih kasar, dan merancang metode pengambilan gambar yang tepat untuk mewujudkan potret 
Michael Sigarlaki, barulah kemudian sutradara bersama kru melakukan proses pengambilan gambar berdasarkan metode yang dipilih, yakni dengan memburu kejadian-kejadian penting seperti momen pertarungan yang tidak dapat terulang kembali, setelah footage pertarungan sudah terkumpul barulah sutradara melakukan interview untuk melengkapi informasi yang tidak diperoleh pada saat mengumpulkan footage, yang mana interview tersebut akan menjadi penguat yang dapat disusun secara tematis di meja editing, setelah melakukan interview sutradara masih tetap memburu momen, yakni momen-momen bersama keluarga dan momen-momen saat melatih Muay Thai yang bisa dilakukan secara lebih santai karena kegiatan tersebut merupakan momen keseharian yang dapat diperoleh secara berkala dalam kurun waktu yang cukup singkat.

Pada pembuatan film dokumenter potret ini, ada keinginan bila penonton sangat tertuju kepada sosok Michael Sigarlaki, sehingga tidak ada narasumber yang akan mendominasi porsi Michael Sigarlaki sebagai tokoh utama dalam film ini, adapun tokoh-tokoh yang muncul di dalam film ini merupakan tokoh-tokoh pelengkap saja, maka untuk melengkapi informasi yang masih kurang lengkap akan digunakan teks penjelasan dan audio yang diperoleh dari proses perekaman interview.
Tipe pendekatan dokumenter yang digunakan adalah cinema verite, tipe ini dirasa sangat cocok diterapkan karena Michael Sigalaki adalah sosok yang aktif berbicara, sehingga dapat dipancing dengan pertanyaan-pertanyaan ringan agar Michael Sigarlaki dapat menyampaikan informasi secara spontan dan lebih ekspresif ke arah kamera bersamaan dengan satu kejadian yang terekam kamera pada saat itu, selain itu tipe pendekatan ini akan menjaga spontanitas sesuai dengan realita yang ada. Namun kekurangan dari tipe cinema verite adalah lebih sulit untuk mengumpulkan informasi secara detail karena membutuhkan waktu dan intensifitas tinggi terhadap subjek, untuk mensiasati kelemahan tipe cinema verite tersebut sutradara sebagai pembuat film akan mengkombinasikan dengan penggunaan gaya expository yang biasa menggunakan audio interview untuk memperkuat pemaparan subjek pada saat footage-footage yang didapatkan tidak mampu memberikan informasi secara rinci.

\section{HASIL DAN PEMBAHASAN}

\section{Segmen Pertama}

Segmen pertama di dalam film “Michael Speed" berperan sebagai pembuka film, sehingga pembahasan yang akan dipaparkan tidak akan dibahas secara terperinci namun tetap memberikan informasi yang jelas dan mudah dipahami oleh penonton. Secara keseluruhan tema yang akan dibahas di segmen petama ini 


\section{Kulsa Angelo, Alexandri Luthfi R., RR. Ari Prasetyowati}

Eksistensi Mantan Petinju sebagai Petarung Pencak Dor Kediri melalui Film Dokumenter Potret "Michael Speed".

adalah pengenalan sosok Michael Speed, adapun sub-sub tema yang akan dibahas di segmen pertama diantaranya, pengenalan tarung Pencak Dor, pengenalan sosok Michael Speed, alasan dan tujuan Michael Speed bertarung di Pencak Dor.

Pengenalan tarung Pencak Dor diwujudkan dengan menggunakan susunan footage yang menggambarkan suasana Pencak Dor yang sekilas tampak seperti pesta rakyat, karena di bawah panggung Pencak Dor terlihat anak-anak sedang bermain-main, kemudian para pemuda berbondong-bondong berdatangan, nampak juga para pemain musik tajidor yang mengiringi lantunan shalawatan untuk mengiringi jalannya pertarungan antara Michael Speed melawan Bimo Aji Putro, suara MC pun lantang membangun semangat ribuan penonton untuk memberi tepuk tangan meriah melihat kepada kedua petarung favorit yang sedang berduel di atas panggung Pencak Dor, suara $M C$ di segmen pertama ini juga berperan sebagai informan yang menggambarkan sosok Michael Speed sebagai petarung kelas berat di Pencak Dor, karena $M C$ tersebut mengatakan "Mas Michael dan Mas Bimo ini adalah partai utama pada malam hari ini."

Secara keseluruhan, gaya penceritaan di segmen pertama banyak menggunakan gaya expository, terlihat dari adanya penggunaan teks penjelasan serta penggunaan audio wawancara sebagai narasi yang akan memberikan informasi sebagai pendukung susunan footage yang disuguhkan. Metode ini digunakan untuk memberikan informasi kepada penonton secara efektif agar memudahkan penonton dalam memahami informasi yang disampaikan.

Pengenalan tokoh Michael Speed dimulai dengan adegan saat ia sedang berlatih sambil memukuli samsak di sasana lamanya di Kediri, kemudian muncul suara monolog Michael Speed yang bersumber dari audio rekaman interview. Terdengar ia memperkenalkan dirinya sebagai mantan petinju nasional yang sekarang berprofesi sebagai petarung Pencak Dor dan pelatih Muay Thai.

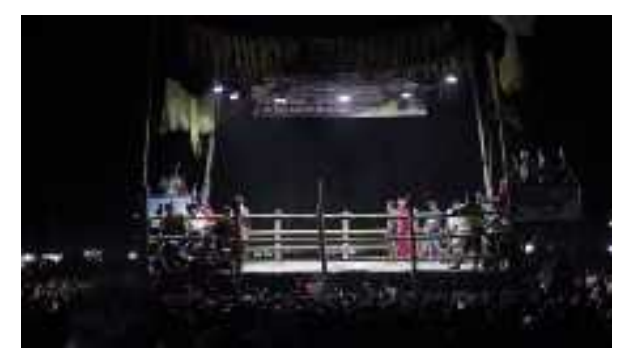

Gambar 1 Suasana pagelaran Pencak Dor Sumber : Film Dokumenter Potret "Michael Speed"

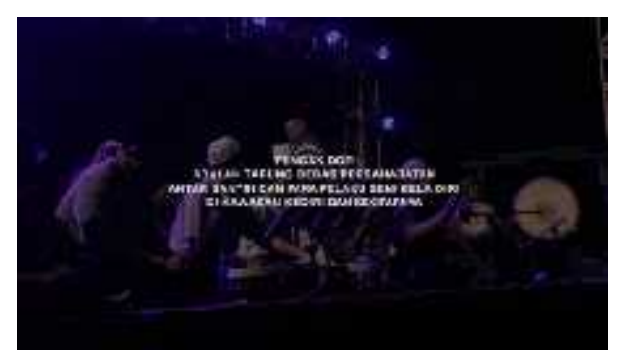

Gambar 2 Teks penjelasan Pencak Dor Sumber : Film Dokumenter Potret "Michael Speed" 


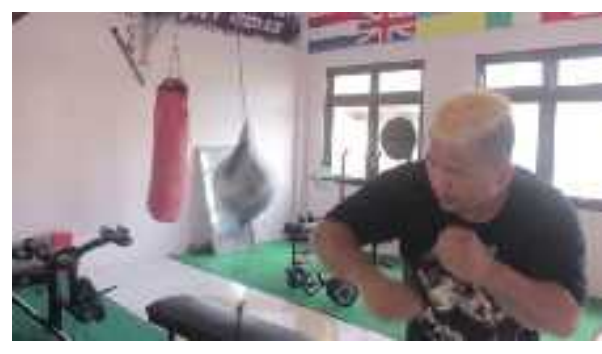

Gambar 3 Michael Speed memukuli samsak Sumber : Film Dokumenter Potret "Michael Speed"

Sebelum memasuki pembahasan mengenai alasan dan tujuan Michael Speed bertarung di Pencak Dor, sutradara ingin menunjukkan dokumentasi Michael Speed semasa ia masih berkarier di tinju profesional, hal ini bertujuan untuk memberikan informasi kepada penonton mengenai latar belakang Michael Speed yang sebelumnya adalah petinju berprestasi. Dalam dokumentasi tersebut terlihat Michael Speed berhasil menjatuhkan lawannya, dan ia berhasil meraih 3 sabuk sekaligus.

Pada interview di segmen pertama Michael Speed mengatakan bahwa ia bertarung di Pencak Dor karena pada waktu itu tinju di Indonesia mengalami masa mati suri yang menyebabkan para petinju tidak memiliki agenda tanding, hingga pada akhirnya ia mendapatkan tawaran untuk bertarung di Pencak Dor, tanpa basa-basi ia pun menerima tawaran tersebut. Ia pun mulai menceritakan debutnya bertarung di Pencak Dor;

\section{Segmen Kedua}

Segmen kedua merupakan inti pembahasan di dalam film dokumenter potret “Michael Speed”, karena di segmen kedua ini potret sosok Michael Speed akan digambarkan dengan visual-visual ataupun momen kejadian yang mencerminkan eksistensi, konsistensi, dan profesionalitasnya sebagai petarung. Ditunjukkan melalui statement dan didukung juga menggunakan shot-shot yang menggambarkan rutinitas Michael Speed sehari-hari.

Secara tematis, sub-sub tema yang dibahas di segmen kedua ini meliputi permasalahan ekonomi terkait dengan profesinya sebagai petarung, rasa takut yang pada akhirnya ia hilangkan berkat passion bertarung yang ia miliki serta eksistensi sebagai petarung yang masih ia pertahankan hingga saat ini, namun secara keseluruhan sub-sub tema tersebut masih dalam satu benang merah yakni bentuk eksistensi Michael Speed sebagai petarung.

Tipe pendekatan Cinema Verite banyak diterapkan di segmen kedua ini, karena di segmen kedua pembuat film banyak merekam aktifitas Michael Speed sehari-hari yang meliputi aktifitasnya bertarung di Pencak Dor ataupun pada saat ia sedang melatih Muay Thai di Gemilang Muay Thai Tulungagung, hal ini dilakukan karena sutradara ingin memunculkan informasi secara spontan bersamaan dengan suatu kejadian yang saat itu sedang terekam oleh kamera, sehingga informasi yang muncul dari Michael Speed akan terasa lebih natural dan menarik. 


\section{Kulsa Angelo, Alexandri Luthfi R., RR. Ari Prasetyowati}

Eksistensi Mantan Petinju sebagai Petarung Pencak Dor Kediri melalui Film Dokumenter Potret "Michael Speed".

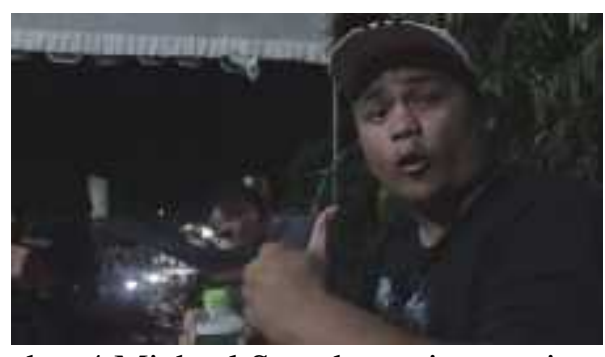

Gambar 4 Michael Speed meminum minuman penambah stamina

Sumber : Film Dokumenter Potret "Michael Speed"

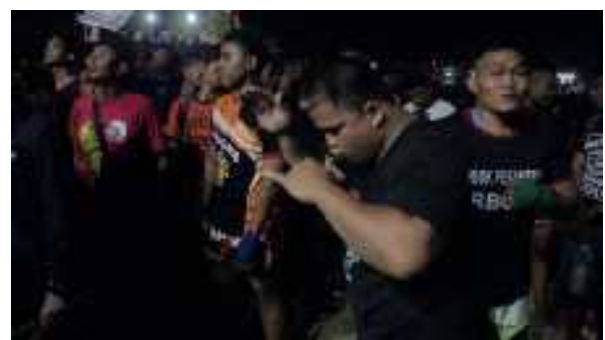

Gambar 5 Michael Speed melakukan pemanasan sebelum bertarung

Sumber : Film Dokumenter Potret "Michael Speed"

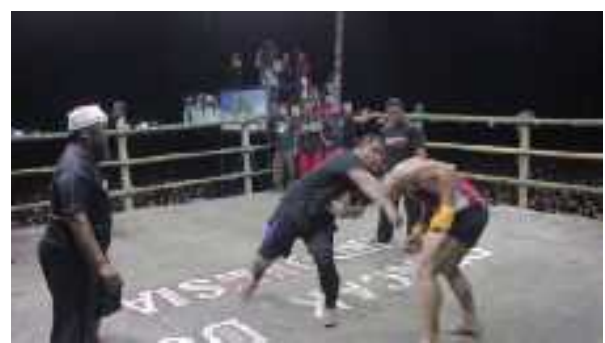

Gambar 6 Michael Speed bertarung melawan Deni Arif

Sumber : Film Dokumenter Potret "Michael Speed"

Kebiasaan yang dilakukan Michael Speed sebelum bertarung adalah melakukan pemanasan ringan, peregangan otot, dan juga meminum minuman penambah stamina, kemudian suara kembang api mulai menggelegar yang menjadi tanda partai puncak pagelaran Pencak Dor segera di mulai, Michael Speed mulai naik ke atas panggung Pencak Dor untuk berhadapan dengan Deni Arif, pertarungan sengit antar keduanya pun terjadi, namun Deni Arif adalah lawan yang tangguh, alhasil pertarungan pada malam hari itu berakhir imbang.

Kegiatan lain Michael Speed selain bertarung Pencak Dor adalah menjadi pelatih Muay Thai di sebuah sasana latihan milik temannya, kegiatan melatih ini juga dibahas di segmen kedua, karena kegiatan ini merupakan salah satu rutinitasnya seharihari. Di dalam sasana itu Michael Speed menjelaskan tentang jadwal melatihnya setiap hari, menurutnya kegiatan melatih adalah metode yang tepat baginya untuk menjaga kebugaran agar jika sewaktu-waktu ada tawaran tarung ia masih bisa bertarung dengan kondisi fisik yang selalu terjaga.

Pada tanggal 2 April 2019, Kota Solo menyelenggarakan pagelaran Pencak Dor Profesional di Stadion Sriwedari, pertarungan ini merupakan pembuktian profesionalitas Michael Speed sebagai petarung Pencak Dor, dalam pertarungan kali ini ia akan melawan petarung Mix Martial Art bernama Indra, keduanya akan saling berhadapan untuk memperebutkan sabuk Pencak Dor Profesional yang pertama kalinya, karena dalam tradisi Pencak Dor di Kediri tidak ada hadiah berupa sabuk ataupun medali.

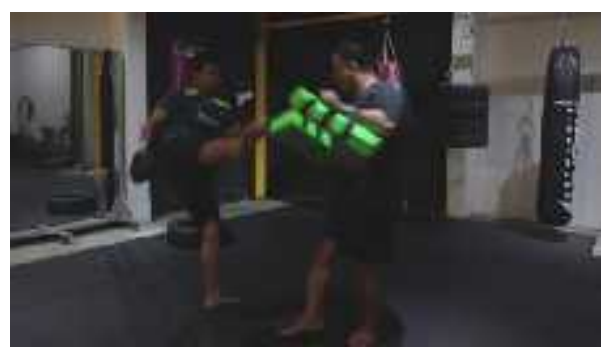

Gambar 7 Michael Speed melatih di Gemilang Muay Thai 


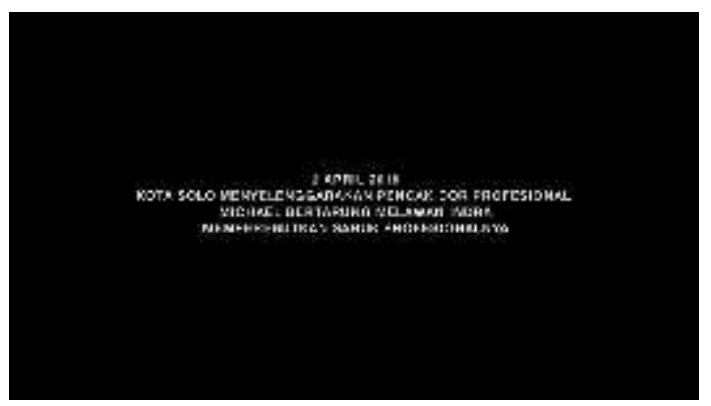

Gambar 8 Penjelasan mengenai diadakannya Pencak Dor Profesional

Sumber : Film Dokumenter Potret "Michael Speed"

Pencak Dor Profesional memiliki aturan yang lebih ketat dibandingkan Pencak Dor tradisional khas Kediri, yakni dengan diperbolehkannya menggunakan sarung tangan, juga terdapat perbedaan area bertarung yang tidak mengguanakan bambu sebagai pembatas area bertarungnya, sekilas Pencak Dor Profesional terlihat seperti arena tarung Mix Martial Art, namun tetap menggunakan gamelan sebagai musik pengiringnya, hal ini disebabkan karena Pencak Dor ini merupakan Pencak Dor modern yang diselenggarakan di Kota Solo yang notabennya memang bukan induk dari kesenian tarung bebas Pencak Dor. Penjelasan mengenai diadakannya Pencak Dor Profesional akan dijelaskan menggunakan teks.

Sore itu di sebuah penginapan, Michael Speed tengah melakukan latihan ringan untuk bersiap-siap menghadapi Indra di arena tarung Pencak Dor Profesional. Dalam sesi latihannya Michael Speed mengatakan bahwa lawannya kali ini memiliki kelemahan yakni pergerakan yang lambat, hal ini tentu menjadi keuntungan baginya, karena ia termasuk petarung yang memiliki pukulan cepat meskipun badannya sangat gemuk untuk ukuran seorang petarung.

Malam hari tiba, pertarungan Michael Speed melawan Indra segera di mulai. Di awal-awal ronde pertama Michael Speed menyerang Indra dengan cukup tenang, Indra pun menyerang balik namun Michael Speed mampu menghindari serangannya, kemudian Michael Speed menyerang Indra dengan serangan bertubi-tubi namun wasit memisahkan keduanya dan ronde pertama selesai. Sebelum memasuki ronde kedua Michael Speed beristirahat sejenak di sudut ring sambil meminum air. Ronde kedua pun dimulai, di ronde kedua Michael nampak lebih serius, ia mencoba mencari celah agar dapat menjatuhkan Indra. Akhirnya ia berhasil memukul pipi Indra hingga gum shield Indra terlepas, Indra pun terjatuh dan wasit memisahkan keduanya, Indra nampak kelelahan dan ingin menyerah, dengan demikian Michael Speed berhasil memenangkan sabuk Pencak Dor Profesionalnya.

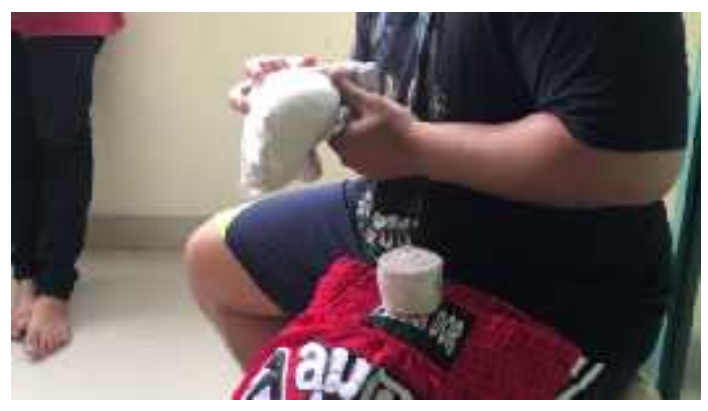

Michael Speed mempersiapkan kebutuhan bertarungnya

Sumber : Film Dokumenter Potret "Michael Speed" 


\section{Kulsa Angelo, Alexandri Luthfi R., RR. Ari Prasetyowati}

Eksistensi Mantan Petinju sebagai Petarung Pencak Dor Kediri melalui Film Dokumenter Potret "Michael Speed".

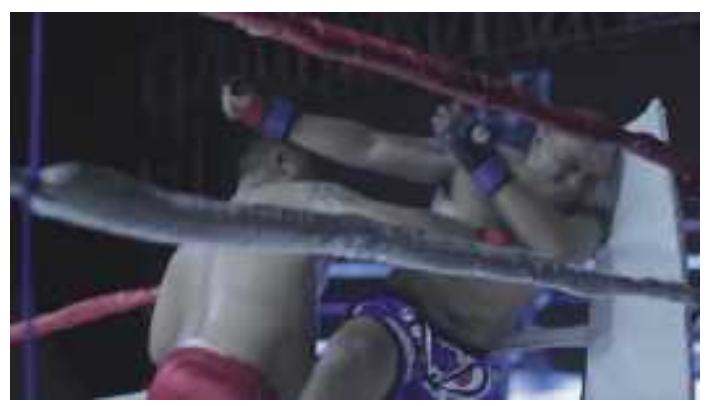

Michael Speed bertarung melawan Indra Sumber : Film Dokumenter Potret "Michael Speed"

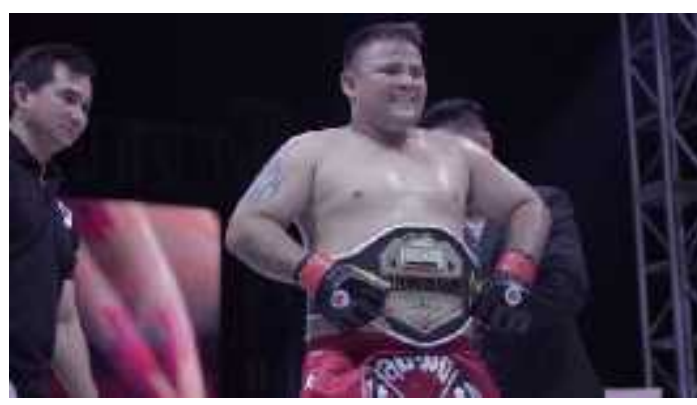

Michael Speed menerima sabuk Pencak Dor Profesional

Sumber : Film Dokumenter Potret "Michael Speed"

\section{Segmen Ketiga}

Segmen ketiga akan menunjukkan sikap humanism sosok Michael Speed yang sangat menyayangi keluarganya. Ia tunjukkan pada saat membelikan mainan untuk anak sulungnya, dan juga momen saat ia mencium anggota keluarganya di rumah. Sikap lembut Michael Speed saat berada di rumah sangat bertolak belakang dengan sikap Michael Speed saat bertarung di Pencak Dor, sisi humanism ini sekaligus memunculkan aspek human interest yang ada di dalam diri Michael Speed. Sedangkan tema yang dibahas di segmen ketiga ini adalah rasa cinta dan kasih sayang terhadap keluarga yang selama ini ia nafkahi dengan cara bertarung.

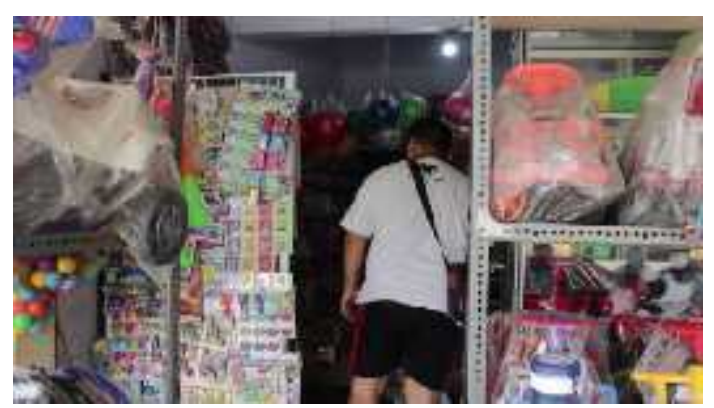

Michael Speed membeli mainan untuk anaknya Sumber : Film Dokumenter Potret "Michael Speed"

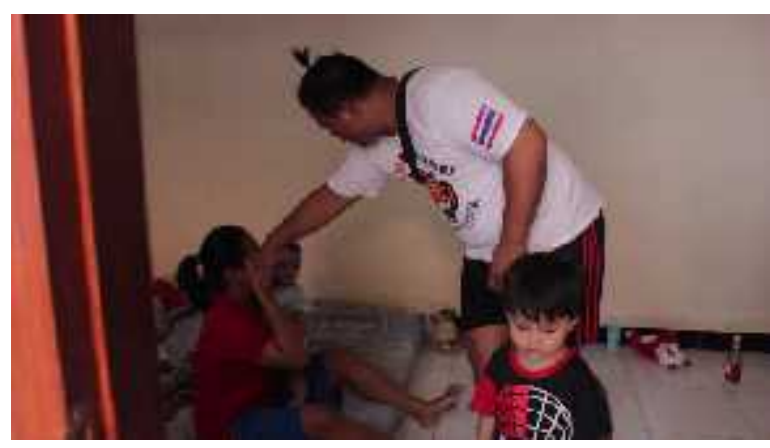

Michael Speed pamit berangkat bekerja Sumber : Film Dokumenter Potret "Michael Speed"

Michael Speed terlihat tengah memasuki toko mainan, di dalam toko mainan tersebut ia mengatakan ingin membelikan mainan untuk anaknya, karena seusai bertarung biasanya ia memiliki uang yang cukup untuk sekadar memberi hadiah kepada anaknya. Saat kembali ke rumah ia memberikan mainan dan pamit berangkat bekerja, sehingga akan tampak jelas sisi humanism Michael Speed sebagai kepala keluarga yang penuh kasih sayang, sikap tersebut sangat bertolak belakang dengan sikapnya saat bertarung di Pencak Dor yang brutal, momen ini memunculkan nilai-nilai human interest dalam diri Michael Speed. 


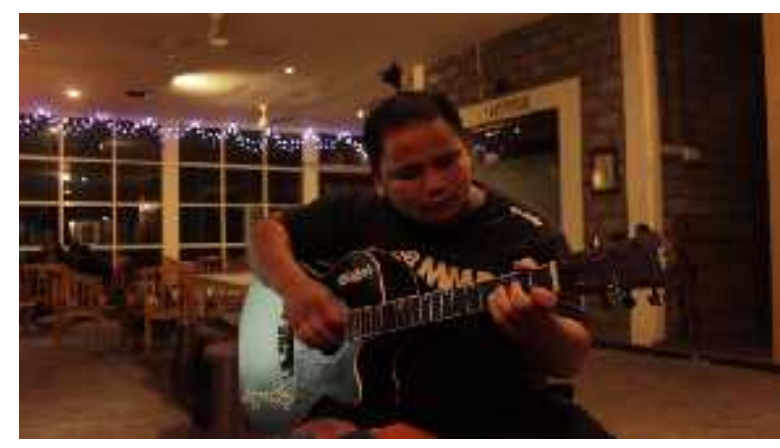

Michael Speed memainkan lagu ciptaannya yang berjudul "Aku Cinta Kamu Tidak"

Sumber : Film Dokumenter Potret "Michael Speed"

Pada interview di segmen terakhir Michael Speed mengaku sudah lelah menjalani karier sebagai petarung, ia juga mengaku bahwa ia sebenarnya ingin berhenti bertarung karena jika terjadi sesuatu pada dirinya maka tidak ada lagi orang yang dapat menghidupi keluarganya, namun untuk saat ini dunia tarung adalah satu-satunya profesi yang dapat ia andalkan untuk mencukupi kebutuhan hidup keluarganya, sehingga ia akan tetap terus bertarung menjadi petarung Pencak Dor yang penuh risiko.

Sebagai penutup film ini, Michael Speed akan menyanyikan lagu ciptaannya dengan menggunakan gitar akustik, melalui karya ciptaannya ia berharap kelak nanti ia dapat berkarier sebagai musisi yang menurutnya akan jauh lebih aman daripada bertarung. Lantunan lagu ciptaan Michael Speed sekaligus menjadi backsound pengiring dalam credit title film dokumenter potret "Michael Speed".

Nilai potret Michael Speed secara keseluruhan dapat disimpulkan menjadi 2 point yakni eksistensi sebagai petarung dan aspek humansime sebagai kepala keluarga. Potret eksistensi sebagai petarung dimunculkan melalui beberapa pertarungan yang ia lakoni, tiap pertarungan serta informasi yang disajikan dalam film ini mewakili nilai-nilai eksistensi, popularitas, passion bertarung, serta pembuktian Michael Speed sebagai petarung profesional. Sedangkan aspek humanisme Michael Speed ditunjukkan melalui aktifitasnya bersama keluarga, kegemarannya membuat lagu cinta, serta besarnya rasa tanggung jawab terhadap keluarga yang ia buktikan melalui pengorbanan dan kerja keras.

\section{KESIMPULAN}

Film “Michael Speed” adalah film dokumenter potret yang dikemas menggunakan struktur bertutur tematis dan menggunakan tipe dokumenter cinema verite juga expository sebagai gaya berceritanya. Film ini mengisahkan kehidupan seorang mantan petinju tanah air yang hingga saat ini masih menjaga eksistensinya di dunia tarung, tepatnya di arena tarung Pencak Dor Kediri, ialah Michael 'Speed' Sigarlaki. Eksistensi dan passion bertarung yang dimiliki membuatnya mampu bertahan dan mengisi jajaran nama-nama petarung terbaik di Pencak Dor Kediri, eksistensinya sebagai petarung ia tunjukkan melalui setiap aksinya di Pencak Dor yang selalu dinantikan oleh masyarakat Kediri, serta kemenangannya melawan Indra dalam memperebutkan sabuk jawara Pencak Dor Profesional Indonesia. 


\section{Kulsa Angelo, Alexandri Luthfi R., RR. Ari Prasetyowati}

Eksistensi Mantan Petinju sebagai Petarung Pencak Dor Kediri melalui Film Dokumenter Potret "Michael Speed".

Penciptaan film dokumenter potret “Michael Speed" merupakan bentuk karya yang sesuai untuk mewakili pemikiran dan perasaan seorang mantan petinju nasional yang memilih jalan hidup sebagai petarung Pencak Dor, kerasnya Pencak Dor diperlihatkan melalui tiap adegan di dalam film ini, serta aksi “Michael Speed" saat menghadapi lawan-lawannya yang merupakan petarung-petarung terbaik di Pencak Dor. Besarnya risiko serta tidak adanya asuransi keselamatan tidak menjadi masalah bagi Michael Speed, karena baginya dunia tarung adalah dunianya, hal ini menyiratkan betapa besar kecintaan Michael Speed terhadap dunia tarung.

Secara keseluruhan film “Michae Speed" membahas 2 tema pembahasan, yang pertama adalah eksistensi dan yang kedua adalah sisi humanism sosok Michael Speed. Bentuk eksistensi Michael Speed sebagai petarung menjadi tema utama dalam film dokumenter potret ini, ditampilkan melalui setiap pertarungan yang ia lakoni, serta pernyataan-pernyataan yang telah ia sampaikan melalui interview di segmen 1 dan 2, sedangkan segmen 3 berisi nilai-nilai humanism yang ditunjukkan dengan bentuk kasih sayang terhadap keluarga serta kepiawaiannya dalam menulis lagu cinta yang secara langsung memunculkan aspekaspek human interest dalam diri Michael Speed.

\section{Daftar Referensi}

Ayawaila, Gerzon R. Dokumenter dari Ide sampai Produksi. Jakarta: FFTV IKJ Press, 2008.

Bernard, Curran, Sheilla. Documentary Storytelling $2^{\text {nd }}$ Edition. United Kingdom: Focal Press, 2007.

Fachruddin, Andi. Dasar-Dasar Produksi Televisi. Jakarta: PT Fajar Interpratama Mandiri, 2012.

Nichols, Bill. Introduction to Documentary. Indiana University Press, Bloomington, 2001.

Peransi, D.A. Film/Media/Seni. Jakarta: FFTV-IKJ Press, 2005.

Pratista, Himawan. Memahami Film. Yogyakarta: Homerian Pustaka, 2008.

Sarwanto. Resep Rahasia: Membangun Rumah Produksi. Yogyakarta: Merdeka Media, 2012.

Tanzil, Chandra. Film Dokumenter Gampang-Gampang Susah. Jakarta: In- Docs, 2010.

Wibowo, Fred. Teknik Produksi Program Televisi. Jakarta: Pinus Book Publisher, 2007. 